Haemoglobin Research Unit, Kitwe, Zambia), and the following staff members of the Ndola Central Hospital: Drs. J. Nag and V. Poonasamy; Messrs. E. Chimolula, J. Wijnands, and J. Mpofu; and Sisters P. Webber, T. Jones, P. Jeffreys, and K. Hannon. Senior Chief Mushili of the Lamba made many follow-up observations possible.

The Permanent Secretary for Health, Zambia, has given M.N.L. and E.C.O'R. permission to publish. Without financial assistance from the Beit Trust and Zambia Copper Mining Companies this investigation would not have been possible. Professor M. S. R. Hutt is supported by the Wellcome Trust.

\section{References}

British Medical fournal, 1967, 4, 614.

British Medical fournal, 1969, 4, 4.
Barclay, G. P. T., Jones, H. I., and Splaine, M. (1970). Transactions of the Royal Society of Tropical Medicine and Hygiene, 64, 78.

Hamilton, P. J. S., et al. (1969). Lancet, 2, 209.

Lowenthal, M. N., Hamilton, J. S., Hutt, M. S. R., and Wilks, N. .E (1966). Central African fournal of Medicine, 12, 99.

Lowenthal, M. N., and Hutt, M. S. R. (1968). East African Medical fournal, $45,100$.

Mancini, G., Carbonara, A. D., and Heremans, J. F. (1965). Immunochemistry, 2, 235.

Marsden, P. D., et al. (1967). Bulletin of the World Health Organization, 36, 901 .

Marsden, P. D., and Hamilton, P. J. S. (1969). British Medical fournal, 1,

Pitney, W. R. (1968). Transactions of the Royal Society of Tropical Medicine and Hygiene, 82, 717.

Sagoe, A.-S. (1970). British Medical fournal, 3, 378.

Stuiver, P. C., Ziegler, J. L., Wood, J. B., Morrow, R. H., and Hutt, M. S. R. (1971). British Medical fournal, 1, 426.

Watson-Williams, E. J., and Allan, N. C. (1968). British Medical fournal, 4, 793 .

\title{
Myocardial Infarction and Deep-vein Thrombosis
}

\author{
A. N. NICOlaides, V. V. KAKKAR, J. T. G. RENNEY, P. H. KIDNER, D. C. S. HUTCHISON \\ M. B. CLARKE
}

British Medical fournal, 1971, 1, 432-434

\section{Summary}

In a study of 52 patients admitted into the coronary intensive care unit the incidence of deep-vein thrombosis was measured with the ${ }^{125}$ I-fibrinogen test. Of these patients 31 were eventually confirmed to be suffering from acute myocardial infarction. This preliminary study showed that in patients with a confirmed infarct who were not treated with anticoagulants the incidence of deep-vein thrombosis was $38 \%$ and in those treated it was $5.5 \%$. In patients who were "severely ill" from whatever the cause there was a high incidence of deep-vein thrombosis $(68 \%)$.

\section{Introduction}

The true incidence of deep-vein thrombosis cannot be estimated clinically because signs are unreliable in diagnosing the condition (Flanc et al., 1968; Negus et al., 1968). The ${ }^{125} \mathrm{I}-$ fibrinogen test, however, is an accurate method of detecting thrombosis at the earliest stage (Atkins and Hawkins, 1965; Flanc et al., 1968; Negus et al., 1968). By using a ratemeter (Kakkar et al., 1970b) the technique is rapid and simple and can be used as a routine-screening procedure in a large number of patients. This technique was adopted in the present study.

In the recent M.R.C. report (1969) post-mortem studies revealed pulmonary embolism in $8.3 \%$ of patients with acute myocardial infarction who died. In a study of 240 consecutive post-mortem reports of patients with acute myocardial infarction at King's College Hospital it was found that

King's College Hospital Medical School, London S.E.5

A. N. NICOLAIDES, F.R.C.s., Pfizer Research Fellow, Department of Surgery

V. V. KAKKAR, F.R.C.s., Lecturer in Surgery

J. T. G. RENNEY, F.R.C.s., Pfizer Research Fellow, Department of Surgery

P. H. KIDNER, M.R.C.P., Research Fellow in Pulmonary Physiology (Present appointment: Senior Registrar in Cardiology) D. C. S. HUTCHISON, M.R.C.P.GLASG., Lecturer, Pulmonary Research

M. B. CLARKE, B.sC., Senior Physicist
$19(7.9 \%)$ had macroscopic pulmonary emboli causing or contributing to their death (Nicolaides, 1970). Similar results have been obtained by others (Browder et al., 1959; Hilden et al., 1961; Kucera, 1966). The present study was prompted by the above findings, which suggested a high incidence of deep-vein thrombosis in association with myocardial infarction. There is no doubt that effective attempts to treat deep-vein thrombosis and prevent pulmonary embolism are more successful when carried out at an early stage (Kakkar et al., 1969).

\section{Patients and Methods}

Fifty-two patients admitted to the coronary intensive care unit were studied. All had been admitted as emergencies with acute chest pain and were well previous to this. Patients aged under 40 and those who had a history or clinical signs of deep-vein thrombosis were excluded. The diagnosis of myocardial infarction was subsequently confirmed in 31 patients according to electrocardiographic and enzymatic (serum aspartate aminotransferase and lactate dehydrogenase) evidence. Eighteen of the patients with a confirmed infarct were treated with anticoagulants. This was part of the routine management practised by some of the physicians under whose care the patients were admitted. In these a continuous intravenous infusion of heparin (10,000 units six-hourly for 36 hours) and oral anticoagulants were started immediately on admission if the infarct was obvious or as soon as it was confirmed, usually within 24 to 48 hours. Subsequently the dose of oral anticoagulants was regulated to maintain the prothrombin time between one and a half and two times the control value. The remaining 13 patients with confirmed infarcts were not treated with anticoagulants (Table I). Apart from anticoagulation both groups received identical treatment.

\section{DIAGNOSIS OF DEEP-VEIN THROMBOSIS}

All the patients were screened by the ${ }^{125}$ I-fibrinogen test, using the Pitman 235 isotope localization monitor (Kakkar et al., 1970b). The principle of this test is that ${ }^{125}$ I-fibrinogen injected into the circulation is incorporated into a forming thrombus, and this is detected by the increased radioactivity at that site. 
TABLE I-Distribution of Patients

\begin{tabular}{cccc|c|c}
\hline & & & Infarct Confirmed & Infarct Not Confirmed \\
\hline Anticoagulants & $\ldots$ & $\ldots$ & $\ldots$ & 18 & 1 \\
No anticoagulants & $\ldots$ & $\ldots$ & $\ldots$ & 13 & 20 \\
\hline Total & $\cdots$ & $\ldots$ & $\ldots$ & 31 & 21 \\
\hline
\end{tabular}

Human fibrinogen was obtained in the form of antihaemophilic factor concentrate (Kabi). This special preparation was extracted from a restricted pool of donors to reduce the risk of serum hepatitis. Carrier-free ${ }^{125} \mathrm{I}$ in sodium hydroxide solution, with a specific activity of $120 \mathrm{mCi} / \mathrm{ml}$, was obtained from the Radiochemical Centre, Amersham, England. The fribrinogen was iodinated, using the "jet iodination" method of McFarlane (1963). Each patient was given $100 \mu \mathrm{Ci}$ of ${ }^{125} \mathrm{I}$-fibrinogen intravenously within 12 hours of admission after blocking the thyroid gland with sodium or potassium iodide. The legs were scanned two hours later, on the following day, and then on alternate days. All patients were examined daily for local tenderness in the calf and thigh and for pitting oedema at the ankle. If the radioactivity increased or if clinical signs of thrombosis developed, the legs were scanned daily. On average the legs were scanned for 10 days. With the Pitman model 235 isotope localization monitor the radioactivity of the various positions in the legs was expressed direct as a percentage of the heart count. Patients were considered to have deep-vein thrombosis when an increase of 20 or more was observed in the percentage value of radioactivity at the same place on two different days or between two adjacent sites, provided that this increase persisted for more than 24 hours (Kakkar et al., 1970b).

\section{Results}

Six of the 31 patients with a confirmed infarct developed deep-vein thrombosis, giving an overall incidence of $19 \%$. Five of these belonged to the group of 13 who did not receive anticoagulants and one to the group of 18 treated with anticoagulants. The incidence of deep-vein thrombosis was $38 \%$ in the former group and $5.5 \%$ in the latter. This difference was significant (Fisher's exact test: $P=0.03$ ). Of the 20 patients who did not have a confirmed infarct and did not receive anticoagulants only $2(10 \%)$ developed deep-vein thrombosis. These were "severely ill." One was in congestive cardiac failure and the other had a dissecting aneurysm. They both died. Out of the whole series of 52 patients eight were "severely ill" (Table II). For the purpose of this paper the

TABLE II-Incidence of DeepVein Thrombosis

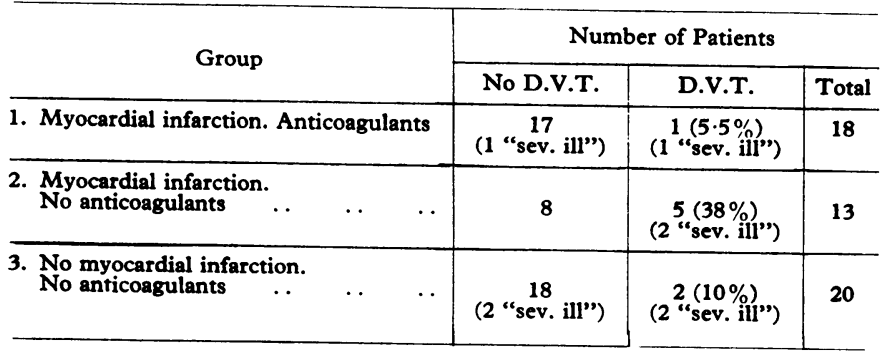

Group 1 compared with group 2: Fisher's exact test : $P=0.03$.

"S.T. = Deep-vein thrombosis.

"severely ill" were patients with a low output state for at least 24 hours as suggested by their low blood pressure, poor peripheral circulation, and low urinary output. In this group of "severely ill" patients there was a very high incidence of deep-vein thrombosis $(62 \%)$ as compared with the not "severely ill" group (7\%) (Table III). This difference was significant (Fisher's exact test: $\mathrm{P}=0.0008$ ).

TABLE III-Incidence in "Severely Ill" Patients

\begin{tabular}{|c|c|c|c|c|c|c|}
\hline & Group & & & No D.V.T. & D.V.T. & Total \\
\hline $\begin{array}{l}\text { "Severely ill" } \\
\text { Not "severely ill"; }\end{array}$ & $\cdots$ & $\because$ & $\therefore$ & $\begin{array}{r}3 \\
41\end{array}$ & $\begin{array}{l}5(62 \%) \\
3(7 \%)\end{array}$ & $\begin{array}{r}8 \\
44\end{array}$ \\
\hline
\end{tabular}

Fisher's exact test : $P=0.0008$

In all the patients who developed deep-vein thrombosis the thrombi were confined to the calf. In two patients the thrombi were bilateral. Thrombi developed in three limbs on day 2 , in two limbs on day 3 , in one limb on day 4 , in one limb on day 5, and in three limbs on day 9. In none of the patients did the thrombi extend into the popliteal or higher regions as judged by the radioactive counts and none had overt clinical evidence of pulmonary embolism.

\section{Discussion}

The findings of this preliminary study support the relatively high incidence of deep-vein thrombosis recently reported in patients with acute myocardial infarction (Murray et al., 1970). Above all, however, they show that those patients who are "severely ill" are by far the most likely to develop deepvein thrombosis $(62 \%)$. It may well be that it is not important what the cause of the "severe illness" is, whether a myocardial infarct or some other condition (Table III).

Despite the small numbers in this pilot study and the fact that patients were not formally allocated prospectively and randomly, the results suggest that anticoagulants may play a part in the reduction of the incidence of deep-vein thrombosis from $38 \%$ to $5.5 \%$ (Table II). Before more reliable results can be obtained regarding the effect of anticoagulation on the incidence of deep-vein thrombosis large numbers of patients should be admitted to a prospective trial and randomly allocated to anticoagulation or no anticoagulation. Precision in the diagnosis of deep-vein thrombosis can be obtained only by using the ${ }^{125}$ I-fibrinogen test. Any future study should determine the relationship between the severity of the myocardial infarction and the incidence of deep-vein thrombosis more accurately. It should also define the high-risk group more precisely.

The present study was confined to the first 10 days after admission to the coronary intensive care unit. It may well be that if the patients had been studied for a longer period a higher incidence of deep-vein thrombosis would have been found.

Most of the patients who have an acute myocardial infarct and die in the coronary intensive care unit are in the "severely ill" group (Lawrie et al., 1967; Lown et al., 1969). The incidence of deep-vein thrombosis of over $60 \%$ in this group may explain the frequency of pulmonary embolism (7.9\%) found by post-mortem studies (Browder et al., 1959; Hilden et al., 1961; Kucera, 1966; M.R.C. Report, 1969; Nicolaides, 1970). Experience in postoperative patients may well serve as a guide in the management of deep-vein thrombosis (Kakkar, 1971). In those over the age of 40 undergoing surgery the incidence of deep-vein thrombosis is $30 \%$ (Kakkar et al., 1970a). In practice the thrombi develop in the veins of the calf, and only in $20 \%$ of those does the process extend more proximally into the popliteal, femoral, or iliac veins. If the process is limited to the calf, for practical purposes, the risk of pulmonary embolism is negligible, but if the popliteal and more proximal veins are thrombosed the risk of pulmonary embolism increases rapidly to about $50 \%$ (Kakkar et al., 1969). It seems then that as regards threat to life it is 
patients with a thrombus above the popliteal who are at risk, and it is in them that anticoagulant therapy is particularly important. This extension of the thrombus can be easily detected with the Pitman model 235 isotope localization monitor, and treatment can be instituted at the proper time.

We are grateful to the physicians of King's College Hospital who allowed us to study patients under their care; to Professor J. G. Murray and Dr. S. Oram for their advice; to Pfizer Ltd. (U.K.) for financing a research fellowship for J.T.G.R.; to the King's College Hospital Research Fund for financial assistance to A.N.N.; and to Mr. S. Serunkuma for invaluable technical help.

\section{References}

Atkins, P., and Hawkins, L. A. (1965). Lancet, 2, 1217.

Browder, F. S., Pérez Olea, J. O., and de Francisco, A. (1959). Archivos de Instituto de Cardiología de México, 29, 31.
Flanc, C., Kakkar, V. V., and Clarke, M. B. (1968). British fournal of Surgery, 55, 742

Hilden, T., Iversen, K., Raaschou, F., and Schwartz, M. (1961). Lancet, 2, 327 .

Kakkar, V. V. (1971). American Heart fournal. In press.

Kakkar, V. V., Howe, C. T., Flanc, C., and Clarke, M. B. (1969). Lancet, 2,230

Kakkar, V. V., Howe, C. T., Nicolaides, A. N., Renney, J. T. G., and Clarke, M. B. (1970a). American fournal of Surgery, 120, 527

Kakkar, V. V., Nicolaides, A. N., Renney, J. T. G., Friend, J. R., and Clarke, M. B. (1970b). Lancet, 1, 540.

Kucera, M. (1966). Vnitrni Lékarstvi, 12, 209.

Kucera, M. (1966). V nitrni Lekarstvi, 12, 209.

Lowrie, D. M., et al. (1967). Lancet, 2, 109. No. 4, p. 261. McFarlane, A. S. (1963). Fournal of Clinical Investigation,
Notion, 42, 346 .

Medical Research Council, Report of the Working Party on Anticoagulant Therapy in Coronary Thrombosis (1969). British Medical Fournal, 1, 335.

Murray, T. S., Lorimer, A. R., Cox, F. C., and Lawrie, T. D. V. (1970) Lancet, 2, 792.

Negus, D., Pinto, D. J., Le Quesne, L. P., Brown, N., and Chapman, M. (1968). British Fournal of Surgery, 55, 835.

Nicolaides, A. N. (1970). Unpublished data.

\title{
Termination of Pregnancy with Intra-amniotic Hypertonic Saline
}

\author{
M. D. G. GILLMER, J. R. FRIEND, R. W. BEARD
}

British Medical fournal, 1971, 1, 434-437

\section{Summary}

Successful therapeutic abortion was performed consecutively by an intra-amniotic injection of hypertonic saline in 102 out of 110 patients in whom the size of the uterus corresponded with a pregnancy of 16 weeks or more.

A spontaneous abortion of the fetus followed the injection alone in 92 of the cases, and the overall injection-delivery interval was 39.75 (range 11-98) hours. In 10 women intravenous oxytocin injection was used as an additional uterine stimulant because contractions were not established after 48 hours. Complete spontaneous expulsion of the placenta occurred in 71 cases, and evacuation of the placenta under general anaesthesia was required in the other 31 .

No major complication occurred among the 110 patients.

\section{Introduction}

With the increase in the number of legal abortions performed in National Health Service hospitals since the passage of the Abortion Act in 1967, termination of pregnancy by the intraamniotic injection of hypertonic saline has been used with increasing frequency, particularly as an alternative to hysterotomy. The technique, originally described by Aburel (1934), has been widely used in Scandinavia to induce midtrimester abortions (Wagner et al., 1962) and to investigate the mechanism of onset of labour (Bengtsson and Csapo, 1962). In Britain the use of both hypertonic glucose and hypertonic saline in cases of missed abortion or intrauterine death has been

Queen Charlotte's Maternity Hospital, London W.6

M. D. G. GILLMER, M.B., B.s., Senior House Officer

Department of Obstetrics and Gynaecolosy, King's College Hospital, London S.E.S

J. R. FRIEND, B.M., M.R.C.o.G., Senior Registrar

R. W. BEARD, M.D., M.R.C.o.G., Senior Lecturer reported (Wood et al., 1962; Millar and Harvey, 1966). Hypertonic saline, however, has not been popular because of the reports of several deaths following its use (Wagatsuma, 1965; Cameron and Dayan, 1966; Frost, 1968; Cameron et al., 1969).

This paper describes the experience from a consecutive series of 110 patients aborted by intra-amniotic hypertonic saline.

\section{Patients and Methods}

All the patients in this series were treated at King's College Hospital or Dulwich Hospital between March 1969 and February 1970. Therapeutic abortion had been agreed to under one or more sections of the Abortion Act of 1967. The main criteria influencing the decision to use this method were that the uterine size should be at least that of a pregnancy of 16 weeks' gestation and that the patient should have no medical condition complicating the pregnancy. The ages of the patients ranged from 15 to 45 years; 23 were under 19 years and 77 were 19 to 30 years. Eighty-four patients were of Caucasian origin and 26 were Negroid.

The intra-amniotic injection of saline was initially performed in the operating theatre, but later it became a routine procedure in the ward. The haemoglobin and blood group of all patients were determined beforehand. Intramuscular pethidine $75 \mathrm{mg}$ and promethazine $25 \mathrm{mg}$ was given one hour before the procedure and all patients were asked to void urine at this time. In those cases where it was not certain that the bladder had been fully emptied catheterization was performed. Vaginal examination was occasionally necessary to locate the uterus accurately in obese patients. In these cases it was found helpful to place a pillow under the patient's back to exaggerate the curve of the lumbar spine.

Strict aseptic precautions were used throughout. The site selected for abdominal puncture was infiltrated with $1 \%$ lignocaine. After this a 9-cm 16-gauge Tuohy needle was introduced direct through the abdominal wall into the uterus. In most cases entry of the needle into the uterine cavity was 